\title{
ESTUDO DO ESCOAMENTO TURBULENTO ATMOSFÉRICO UTILIZANDO ENSAIOS EM TÚNEL DE VENTO E SIMULAÇÃO NUMÉRICA
}

\author{
DANIEL SCHUCH ${ }^{1}$, EDSON R. MARCIOTTO ${ }^{2}$, OTÁVIO ACEVEDO ${ }^{3}$, GILBERTO FISCH ${ }^{2}$, ANA \\ CRISTINA AVELAR ${ }^{2}$
}

\author{
${ }^{1}$ Instituto Nacional de Pesquisas Espaciais (INPE), Santa Maria, RS, Brasil \\ ${ }^{2}$ Instituto de Aeronáutica e Espaço (IAE), São José dos Campos, SP, Brasil \\ ${ }^{3}$ Universidade Federal de Santa Maria (UFSM), RS, Brasil
}

underschuch@gmail.com, emarciotto@yahoo.com, otavio@ufsm.br, fisch.gilberto@gmail.com, anacristina. avelar@gmail.com

Recebido Janeiro de 2013 - Aceito Setembro de 2013

\begin{abstract}
RESUMO
A estrutura do campo de vento e da turbulência atmosférica gerada no interior de uma cavidade rasa é analisada com o uso de ensaios realizados em túnel de vento e simulação numérica com um modelo bidimensional de grandes turbilhões (LES). As cavidades são maquetes estáticas, que podem representar regiões de pequenas clareiras na Amazônia ou de "canyons" urbanos representando a geometria de cidades modernas. Os resultados sugerem que, apesar das diferenças de escalas, a organização da turbulência nos dois experimentos contém similaridades em algumas regiões. Foi verificada a dependência que a intensidade da turbulência, o perfil do vento e termos do balanço de Energia Cinética Turbulenta têm com a velocidade do fluxo livre, com as dimensões (largura) da cavidade e com a posição relativa dentro da cavidade.

Palavras-chave: clareira, energia cinética turbulenta, perfil do vento, anemômetro de fio quente, modelos LES,

ABSTRACT: INVESTIGATION OF THE ATMOSPHERIC TURBULENT FLOW USING WIND TUNNEL TESTS AND NUMERICAL SIMULATION

The structure of the wind field and atmospheric turbulence generated inside a shallow cavity is analyzed using wind tunnel tests and a 2-D Large-Eddy Simulation (LES) model. The cavities are static mock-up that can represent small clearings inside forest in Amazonia or urban canyons representing the geometry of modern cities. The results suggest that, despite differences in the scales, the organization of turbulence in the two experiments contains similarities in some regions. It was verified the dependency of the turbulence, wind profile and Turbulent Kinetic Energy dependence against flow above canopy, its size and its relative position inside the gap.
\end{abstract}

Keywords: clearing, turbulent kinetic energy, wind profile, hot wire anemometry, LES model

\section{INTRODUÇÃO}

Uma cavidade rasa sobre a qual o escoamento atmosférico passa é uma geometria básica encontrada, por exemplo, em cânions urbanos compostos de prédios e ruas ou, no caso específico da Amazônia, em pequenas clareiras inseridas em áreas de floresta tropical. A interação entre o vento externo e a geometria da cavidade produz um regime de circulação atmosférica controlado por regiões de auto-oscilações (Yao et al., 2000).
O estudo das características de clareiras abertas em florestas é altamente interdisciplinar e envolve ciências de ecologia, manejo florestal, meteorologia, química, entre outras, sendo todas relacionadas entre si. Estudos de Raupach et al. (1996), Neff e Merohney (1998), Aubrun et al. (2004) e Rodrigo et al. (2007) empregam ensaios de túnel de vento para simular o comportamento de uma cavidade com diferentes porosidades com o uso de modelos físicos construídos com vários tipos de materiais e tendo diversas técnicas para a medição da velocidade 
do vento. Comparações entre dados obtidos com florestas e simulados em modelos de grandes turbilhões (Large-Eddy Simulation, LES), pode ser encontrado em Patton et al. (1998) onde os efeitos de uma descontinuidade de floresta e pastagem foram estudados por meio da caracterização dos termos do balanço de momentum e transporte de escalares.

Além disso, até recentemente, as observações meteorológicas de superfície de áreas de floresta eram coletadas em clareiras artificiais cercadas por florestas que podem não representar adequadamente as características das florestas (Raupach e Thom, 1981). Assim, o escoamento atmosférico em áreas de florestas e clareiras pode ser simulado em túnel de vento, usando de uma maquete no formato de cavidade. Atualmente, em alguns poucos casos, dados para caracterizar o escoamento atmosférico sobre regiões de florestas são feitos por torres micrometeorológicas instrumentadas acima do dossel, sem o desmatamento (Kruijt et al., 2000, Von Randow et al., 2004), o que obviamente representa melhor o escoamento de floresta. Porém, a grande maioria das estações meteorológicas ainda são instaladas dentro de clareiras.

O objetivo deste artigo é o de avaliar o regime de circulação atmosférica no interior de uma cavidade rasa e seu acoplamento com o escoamento livre, através do uso de ensaios em túnel de vento e de modelagem numérica, considerando o caso bidimensional. As cavidades com a razão da largura $(L)$ pela profundidade ou altura $(h)$ maiores que 1 são chamadas de cavidades rasas, sendo que neste trabalho serão investigadas 3 cavidades com razões $(L / h)$ diferentes.

\section{MATERIAL E MÉTODOS}

Os resultados foram obtidos a partir de ensaios em túnel de vento atmosférico e de simulações numéricas de um modelo LES. O túnel de vento utilizado, TA-3, está localizado na Divisão de Aerodinâmica (ALA) no Instituto de Aeronáutica e Espaço (IAE), São José dos Campos, Brasil. A simulação do modelo LES, baseado no código descrito por Smolarkiewicz e Margolin (1997), foi realizada em um computador Sony Vaio VGN-NW240F (processador Intel ${ }^{\circledR}$ Core ${ }^{\mathrm{TM}}$ Duo, CPU T6600 2x 2.2GHz, sistema Linux distribuição Xubuntu 64-bit), totalizando 360 minutos simulados, processadas por 99 minutos.

\subsection{Conjunto de dados de túnel de vento}

O TA-3 (Figura 1) possui uma circulação fechada, sendo que a sessão de teste é aberta e circular (aproximadamente $0,65 \mathrm{~m}$ de diâmetro e 1,0 $\mathrm{m}$ de comprimento entre a saída e reentrada). O perfil de vento na borda de entrada da cavidade foi medido e aproximava-se de um perfil de vento típico observado na atmosfera para região de floresta. A intensidade da turbulência presente no túnel vazio (sem modelo da cavidade) é em torno de $0,3 \%$, para velocidade de $30 \mathrm{~m} / \mathrm{s}$ (Avelar et al., 2009).

O modelo físico de cavidade foi construído com madeira polida. Possui altura fixa $(h=43 \mathrm{~mm})$ e largura variável permitindo a variação da razão de aspecto $(L / h)$ da cavidade. Nesse conjunto de experimentos foi obtido o perfil vertical de velocidade nas alturas normalizadas $z / h=0,1 ; 0,3 ; 0,5 ; 0,7$; 0,$9 ; 1,0 ; 1,1 ; 1,5 ; 2,0$ e 2,5 em relação à depressão do modelo (como ilustrado na Figura 1), sendo que o eixo $x$ (longitudinal) está alinhado com a velocidade do vento médio e a origem está no início da cavidade. Foram obtidos perfis longitudinais ao longo do eixo em posições múltiplas de $h$ no interior da cavidade. As medidas foram realizadas considerando-se três valores de razão de aspecto $(4,6$ e 8$)$, sendo que para cada valor (a)
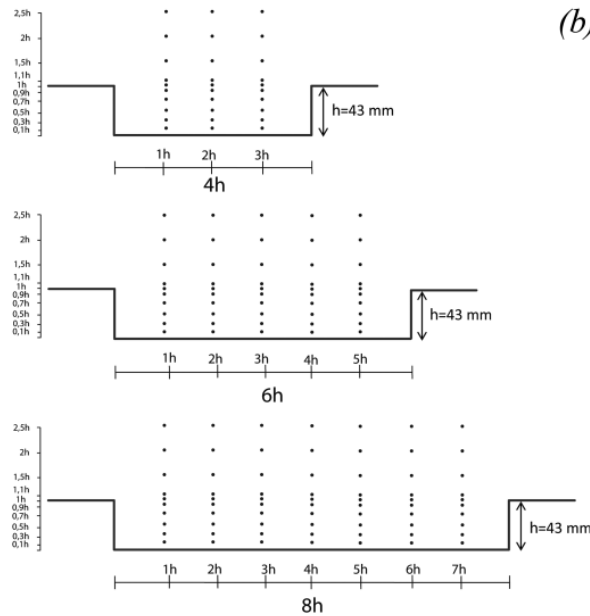

(b)

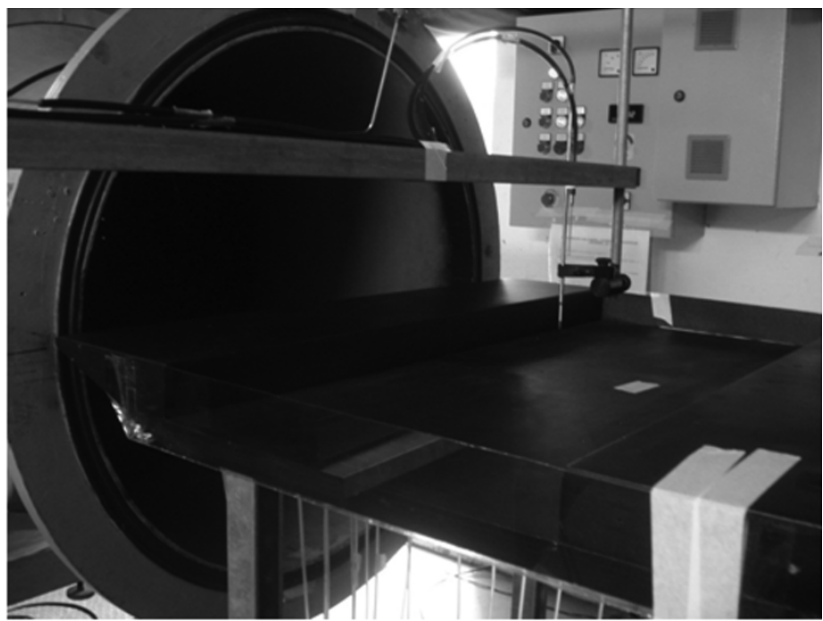

Figura 1 - Representação esquemática (a) mostrando os pontos onde foram realizadas medidas no interior das cavidades $4 \mathrm{~h}$, $6 \mathrm{~h}$ e $8 \mathrm{~h}$ e (b) maquete da cavidade inserida no interior do túnel de vento. 
se considerou as velocidades de 2,5 e $10 \mathrm{~m} / \mathrm{s}$ (totalizando 9 ensaios). Devido ao fato de que o túnel não possui estratificação térmica, salienta-se que apenas as situações de estabilidade neutra foram ensaiadas. O número de Reynolds $(\mathrm{Re})$ obtidos nos ensaios é da ordem de $10^{4}$, que é inferior ao observado na atmosfera (normalmente na ordem de $10^{6}$ conforme sugerido por Lim et al., 2007 ou ainda $10^{7}$ conforme observado por Berg et al., 2011).

No que diz respeito ao número de Re para o túnel de vento $\left(10^{4}\right)$, este é um valor relativamente alto, no qual a turbulência é suficiente para ser caracterizada como bem desenvolvida (Rodrigo et al., 2007). Neste artigo, os autores analisam o comportamento do vento e da turbulência em uma área de clareira, visando aplicações de estimativa de vento para levantamento de potencial eólico. Por outro lado, Wyngaard (2010) menciona que, para valores acima de um valor crítico, a energia contida nos vórtices torna-se independente do Re, permitindo o uso de modelos de laboratório (túnel de vento e/ ou tanque de água) para representar os escoamentos geofísicos com Re mais elevado.

As medidas de velocidade do vento foram realizadas com um sistema de anemômetro de fio quente da Dantec Dynamics System, constituído de uma sonda unidirecional, placas de aquisição e conversão analógico/digital. A taxa de amostragem escolhida foi de $1000 \mathrm{~Hz}$ por um intervalo de aproximadamente 1 minuto (65536 ms). A calibração foi feita em uma unidade de calibração da Dantec Dynamics e foi escolhido um intervalo de velocidade do vento de $0,1 \mathrm{a} 12,0 \mathrm{~m} / \mathrm{s}$, que inclui toda gama de velocidades esperadas durante o experimento.
Salienta-se que a velocidade medida pelo anemômetro de fio quente não representa a velocidade longitudinal do escoamento, mas sim uma velocidade efetiva $\left(U_{\text {eff }}\right)$ que é uma combinação das componentes das velocidades que segue a seguinte relação:

$$
U_{e f f}^{2}=u^{2}+\gamma^{2} v^{2}+\lambda^{2} w^{2}
$$

onde $u_{i}=(u, v, w)$ é a velocidade do vento na direção $x_{i}=(x, y, z)$, $\gamma=\gamma(\alpha)$ e $\lambda=\lambda(\theta)$ são funções dos ângulos de incidência e elevação, respectivamente. Como a componente $v$ ao longo do fio é praticamente zero, e testes de sensibilidade realizados por Jorgensen (1971) determinaram $\lambda$ entre 1,02 e 1,04 para o intervalo de 20 a $90^{\circ}$, isso implica em:

$$
U_{e f f} \approx \sqrt{u^{2}+w^{2}} \text {. }
$$

Outras medidas experimentais já foram realizadas com o mesmo modelo de cavidade rasa e túnel de vento, com o uso, por exemplo, de técnicas de velocimetria por imagem de partículas PIV (do inglês, Particle Image Velocimetry), onde um conjunto de partículas traçantes é liberado no fluído (no caso o ar) e a partir das imagens de suas posições em diferentes intervalos de tempo, são determinados campos bidimensionais de velocidade como os da Figura 2 (Avelar et al., 2009). Essas medidas sugerem que na região interna da cavidade há a formação de uma célula de recirculação (com 1 vórtice), evidenciadas pelas linhas de correntes fechadas (linhas cheias), assim como, pela inversão do sentido do vento, dado pela componente do vento zonal nula e representada pela linha pontilhada, associadas à região de baixa velocidade do fluxo.

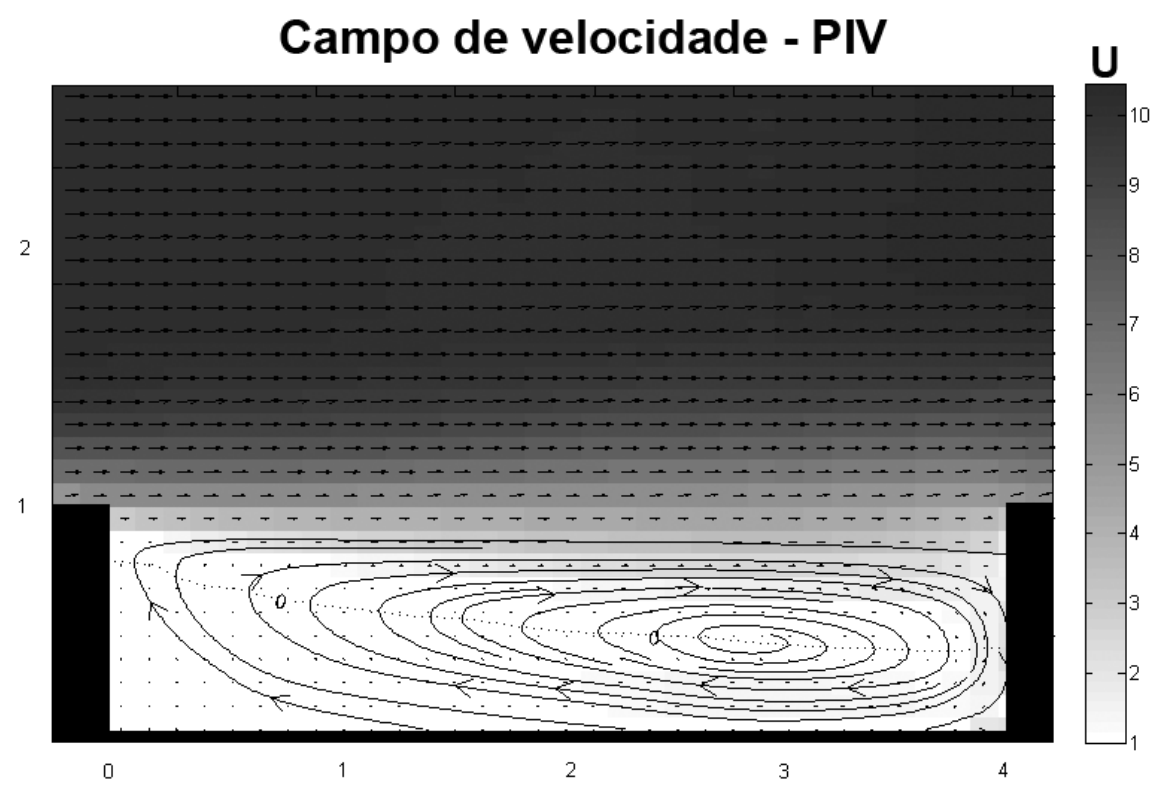

Figura 2 - Campos de velocidade extraídos do túnel de vento com o uso de PIV. Tons de cinza mais escuros correspondem a maiores velocidades, linhas cheias são linhas de corrente e a linha pontilhada é onde a componente horizontal do vento é zero. A unidade nas direções x e z é adimensionalizada por $h$. 


\subsection{Simulação numérica}

Simulações numéricas têm sido empregadas no estudo do escoamento atmosférico na Camada Limite Planetária (CLP) sob várias condições físicas e diferentes escalas temporais e espaciais (Bitencourt e Acevedo, 2008). Devido à estrutura essencialmente turbulenta da CLP, um procedimento bem estabelecido para este tipo de estudo, de acordo com Mason (1994), é o emprego de modelos LES, sendo que estes modelos numéricos resolvem explicitamente a estrutura dos grandes turbilhões e parametrizam os processos de pequena escala, sendo usados tanto para simular as propriedades de escoamentos turbulentos, como para fornecer detalhes sobre o escoamento. O modelo LES usado neste estudo (Smolarkiewicz e Margolin, 1997) é baseado em um sistema de equações diferenciais que representam a conservação do momentum médio (Equação 3), massa (Equação 4) e primeira lei da termodinâmica (Equação 5), descritos a seguir

$$
\begin{aligned}
\frac{d \bar{u}_{i}}{d t} & =-\frac{1}{\rho} \frac{\partial \bar{p}}{\partial x_{i}}+\delta_{i 3} g \frac{\bar{\theta}-\theta_{0}}{\theta_{0}}+D_{u_{i}}+F_{i} \\
\frac{\partial \bar{u}_{i}}{\partial x_{i}} & =0 \\
\frac{d \bar{\theta}}{d t} & =D_{\theta}
\end{aligned}
$$

onde $t$ é o tempo, $\rho$ a densidade do ar, $p$ a pressão atmosférica, $\delta_{i 3}$ o delta de Kronecker, $\bar{\theta}$ e $\theta_{0}$ são temperatura potencial virtual e a temperatura do estado de referência, constante com a altura. Os termos $D_{u_{i}}$ e $D_{\theta}$ são parametrizações da subgrade do LES como descrito em Sorbjan (1996):

$$
\begin{aligned}
& D_{\theta}=-k_{h} \nabla^{2} \bar{\theta} \\
& D_{u_{i}}=-k_{m} \nabla^{2} \bar{u}_{i}
\end{aligned}
$$

onde $k_{h}$ e $k_{m}$ são os coeficientes de difusão turbulenta de $\bar{\theta}$ e $\bar{u}_{i}$ na direção $i$, que são função da energia cinética turbulenta de (ECT) subgrade, comprimento de mistura e número de Prandtl. O efeito da fricção exercida pelos obstáculos que estão ao redor da cavidade é incluído explicitamente na equação do momentum médio (Equação 3), como sendo um termo sumidouro de momento $\left(F_{i}\right)$ oposto ao vetor local e instantâneo do vento exceto acima da altura da cavidade e na região interna da cavidade, onde é nulo, sendo descrito em Shaw e Schumann (1992):

$$
\begin{aligned}
F_{i} & =H\left(\left|x-x_{c}\right|-L / 2, z-h\right) A_{i} \\
A_{i} & =-c_{d} a U \bar{u}_{i}
\end{aligned}
$$

onde $H$ é uma função degrau de Heaviside, $x_{c}$ é a posição do centro da cavidade de largura $L=120 \mathrm{~m}$ e profundidade $h=$ $20 \mathrm{~m}, A_{i}$ o termo de arrasto, $c_{d}$ o coeficiente de arrasto e $U$ o módulo da velocidade do vento e $a$ é definido como a razão $a$ $=S_{i} / V$, onde $S_{i}$ é a área da sessão na direção $i$ e $V$ o volume da grade.

O domínio espacial da simulação numérica é um corte bidimensional de uma cavidade de $360 \mathrm{~m}$ de comprimento e $70 \mathrm{~m}$ de altura, suficientes para que os "efeitos de borda" causados pelas condições de contorno no topo do domínio não afetem a região próxima ao do interior da cavidade, dividido na horizontal em 90 pontos em intervalos de $4 \mathrm{~m}$ e em 36 níveis com espaçamento regular de $2 \mathrm{~m}$ na vertical (coordenada $z$ ). As condições de contorno são fixas no sentido do vento médio (eixo $O x$ ), a condição de contorno inferior é a superfície e a superior é uma barreira rígida sem fricção e onde as trocas de massa, momentum, calor e energia cinética turbulenta são iguais a zero. Essa condição artificial pode ser considerada como sendo uma forte inversão térmica no topo da camada e uma barreira sólida na superfície (Sorbjan, 1996).

Para a condição inicial foi escolhido um perfil vertical de temperatura potencial constante igual a $290 \mathrm{~K}$ (equivalente a aproximadamente $17{ }^{\circ} \mathrm{C}$, que foram as temperaturas do ar durante as medidas no túnel de vento), com fluxo de calor nulo para induzir uma estabilidade atmosférica neutra, uma atmosfera seca (considerando-se o valor zero de umidade específica), além de um perfil do vento em equilíbrio (Panofsky e Dutton, 1984) em todo domínio, exceto no interior da cavidade, onde ele é inicialmente nulo. Esta condição inicial representa a condição de neutralidade similar aos ensaios realizados no túnel de vento e procura-se dar ênfase nos efeitos da turbulência mecânica sobre o escoamento, tais como, a geração de estruturas organizadas (recirculações) e turbulência mecânica gerada por cisalhamento. O número de Reynolds para esse conjunto de simulações variou entre $3 \times 10^{6}$ e $1,4 \times 10^{7}$, que estão dentro da faixa de variação de Re observado na atmosfera (Lim et al., 2007 e Berg et al., 2011).

Para a simulação numérica foi escolhido um passo de tempo de integração de $0,1 \mathrm{~s}$ e simulado um total de 12000 passos de tempo (equivalente a 20 minutos), onde os primeiros 10 minutos foram considerados como um intervalo de tempo para o modelo atingir o equilíbrio numérico (solução numérica convergir para a solução real das Equações Diferenciais Parciais que descrevem o modelo) e também tempo para os fenômenos transientes de escala de tempo muito maior do que os fenômenos de interesse tenham entrado em equilíbrio. Os dados nesses primeiros minutos foram considerados spin up do modelo e desprezados, sendo que o restante do tempo foi utilizado para as análises.

\subsection{Comparação das escalas de velocidade e turbulência}

Nessa sessão será abordada a metodologia usada para comparar os perfis de velocidade, turbulência e escala de 
comprimento da turbulência, tanto dos ensaios de túnel de vento, como dos resultados das simulações bidimensionais em LES. Essa comparação apresenta dificuldades que vão além das diferenças contidas nas séries de dados, tais como taxas de amostragem, comprimento da série temporal e escalas de comprimento envolvidas muito diferentes. Os principais aspectos que devem ser considerados são as limitações particulares presentes, tanto nos ensaios no túnel de vento, como na simulação numérica. A geometria não homogênea do escoamento no interior da cavidade é outra característica que deve ser considerada.

Para uma comparação entre os dois conjuntos de dados (as simulações numérica do LES e os ensaios de túnel de vento), primeiramente é necessário transformar a velocidade obtida pelas simulações numéricas na mesma forma que a velocidade do túnel de vento, medido pelo sensor de fio quente, usando a Equação 2, o que provoca uma perda de informação relacionada à direção do vento (o sinal da velocidade efetiva é sempre positivo). Sendo assim, o sensor não distingue a diferença no sentido do vento, apenas estima a velocidade de acordo com a taxa de resfriamento no fio quente. As componentes do vento foram extraídas da grade resolvida do LES, a cada passo de tempo, em posições correspondentes aos pontos onde foi instalado o sensor de fio quente nos ensaios do túnel de vento (veja Figura 1a).

Os termos da equação de balanço de Energia Cinética Turbulenta (ECT) sob condições estacionárias e não homogêneas pode ser descritos como (Stull, 1988):

$$
\overline{u_{i}} \frac{\partial \bar{e}}{\partial x_{i}}+\frac{1}{\rho} \frac{\partial \overline{u_{i}{ }^{\prime} p^{\prime}}}{\partial x_{i}}=\delta_{i 3} \frac{g}{\bar{\theta}}\left(\overline{u_{i}{ }^{\prime} \theta^{\prime}}\right)-\overline{u_{i}{ }^{\prime} u_{j}{ }^{\prime}} \frac{\partial \bar{u}_{i}}{\partial x_{j}}-\frac{\partial\left(\overline{\left.u_{i}{ }^{\prime} e^{\prime}\right)}\right.}{\partial x_{i}}-\mathcal{E}
$$

$$
\begin{array}{llllll}
\text { I } & \text { II } & \text { III } & \text { IV } & \text { V } & \text { VI }
\end{array}
$$

onde os termos do lado esquerdo (termos de transporte) são a advecção de ECT pelo vento médio (termo I) e o transporte de ECT por perturbação de pressão (II). Os termos do lado direito são: empuxo (III), produção/perda de ECT por cisalhamento do vento (IV), termo de mistura turbulenta (V) e um termo de dissipação (VI). Cabe salientar que o modelo numérico LES resolve explicitamente todos os termos desta equação, mas por motivos de comparação com os ensaios de túnel de vento, os termos (III, IV e VI) serão calculados diretamente dos campos de vento e os termos de transporte serão calculados com o resíduo da Equação 10. Uma outra técnica passível de ser utilizada seria as integrações DNS, mas que foge aos objetivos deste trabalho.

Este procedimento permite avaliar melhor a influência, tanto dos grandes vórtices (escala resolvida), como das condições físicas impostas (iniciais e de contorno) aos modelos (físico e numérico) na geração e dissipação de ECT. Porém, os efeitos transientes (em escalas de tempo muito maiores que os fenômenos de interesse) nas variáveis momentum e ECT são aproximadamente constantes, quando se faz uma média nesses intervalos de tempo.

Outra quantidade importante na análise da turbulência é o espectro de energia turbulenta que é dividido em três regiões: uma região de produção de turbulência, uma região inercial e uma região de dissipação (Arya, 1999). A relação entre as regiões também é conhecida como cascata de turbilhões, onde a energia é gerada pelos vórtices de maiores comprimentos de onda e passa para as menores escalas até a dissipação. Dessa forma, o espectro pode ser usado para identificar a importância das várias escalas envolvidas no desenvolvimento e manutenção da turbulência.

No caso do conjunto de dados do túnel de vento, o espectro de energia pode ser extraído diretamente da série de dados de velocidade do vento assumindo a hipótese de Taylor (Stull,1988) restrita às regiões imediatamente próximas ao ponto e aplicando uma transformada de Fourier, que transforma o sinal do domínio do tempo $(t)$ para o domínio da frequência ou para o número de onda (Boyce e Diprima, 2002). Já para o caso dos resultados da simulação em LES, que possui uma grande sensibilidade ao tipo de parametrização da sub-grade utilizada, não é esperado que a menor escala resolvida represente efetivamente o espectro, pois os valores representam médias em ponto de grade em um intervalo $\Delta x_{i}$. Para uma comparação apropriada, os valores médios são multiplicados por uma função de filtro unidimensional (Schmidt e Schumann, 1989), a saber:

$$
F_{i}\left(k_{i}\right)=\left[\frac{\sin \left(k_{i} \Delta x_{i} / 2\right)}{k_{i} \Delta x_{i} / 2}\right]^{2}
$$

onde $k_{i}$ é o número de onda na direção $x_{i}$. A convenção de somatório não se aplica a essa equação. Para campos tridimensionais diferentes filtros devem ser aplicados como em Moeng e Wyngaard (1988), porém o filtro definido pela Equação 11 aplicado na variável $u$ é suficiente para o presente trabalho.

Uma das principais informações presentes no espectro de energia é a frequência que ocorre o pico de energia turbulenta $k_{i}$ e o intervalo em que a produção e dissipação da turbulência estão em equilíbrio (intervalo inercial). Dessa forma, pode-se estimar a escala de comprimento integral $\sim 1 / k_{i}$ associada aos turbilhões mais energéticos. Note que $\Lambda_{u_{i}}=\pi / k_{i}$ é a escala de comprimento integral euleriano (Foken, 2006), que pode ser definida para cada componente do vento como:

$$
\begin{aligned}
\Lambda_{u_{i}} & =U_{i} T_{a}=U_{i} \int_{0}^{\infty} \rho_{u_{i}}(\xi) d \xi=U_{i} \int_{0}^{\infty} \frac{\overline{u_{i}(t) u_{i}(t+\xi)}}{\sigma_{u_{i}}^{2}} d \xi \\
& =U_{i} \int_{0}^{\infty} \frac{u_{i}\left(k_{i}\right) u_{i}\left(k_{i}+\xi\right)}{\sigma_{u_{i}}^{2}} d \xi
\end{aligned}
$$


onde $T_{a}$ é a escala integral de tempo, $U_{i}, \sigma_{u_{i}}^{2}$ e $\rho_{u_{i}}(\xi)$ são a média, a variância e a função de autocorrelação de cada componente de $u_{i}$ para uma determinada altura.

Para o caso de um escoamento estacionário, os desviospadrão de cada componente da velocidade são constantes, também chamados de características integrais da turbulência (Tillman, 1972) caracterizando um estado integral da turbulência para todas as frequências. Para as características integrais de cada componente do vento, os seguintes valores foram encontrados em Foken (2006):

$$
\begin{aligned}
& \sigma_{u} / u_{*} \cong 2,45 \\
& \sigma_{w} / u_{*} \cong 1,25
\end{aligned}
$$

sendo válidos para um fluído com estratificação neutra. Essas relações foram utilizadas para o cálculo do termo de mistura turbulenta (termo IV).

Uma vez determinado o intervalo inercial, o termo de dissipação presente na Equação 10 pode ser calculado com o espectro $E_{u_{i}}(k)$ e pela lei dos $-5 / 3$ de Kolmogorov:

$$
E_{u_{i}}(k)=\beta_{u_{i}} \varepsilon^{2 / 3} k^{-5 / 3}
$$

onde $\beta=0,52$ é a constante de Kolmogorov (Stull, 1988).

Uma concordância estreita entre simulações numéricas em LES e o previsto pela teoria, só pode ser esperada quando a resolução é suficientemente fina, a ponto de resolver até mesmo a porção menos significativa do final do intervalo inercial (Schmidt e Schumann, 1989). De outro modo, o espectro obtido numericamente é influenciado, tanto pela estrutura de larga escala, como pelas aproximações de diferenças finitas.
As simulações numéricas em LES estão dentro desses limites restritos e foi possível determinar algumas grandezas com base no espectro da energia turbulenta de perfis de velocidade do vento da grade resolvida.

\section{RESULTADOS E DISCUSSÃO}

Cabe salientar que as análises e discussões apresentadas aqui são baseadas em simulações numéricas em LES bidimensional e em ensaios em túnel de vento com um modelo de cavidade de geometria simples. Os perfis analisados foram obtidos por meio de uma única variável que contém a informação das componentes $u$ e $w$ da velocidade, tanto no caso do LES, como nos dados do túnel de vento. Ressalta-se também que as medidas mais próximas da superfície foram realizadas na altura $\mathrm{z} / \mathrm{h}=0,1$ e que há um maior transporte vertical de momentum no ensaio do TA-3 do que nas simulações pelo LES.

A Figura 3 mostra o campo médio de velocidade simulado em LES para a cavidade com tamanho $4 h$ e velocidade do fluxo livre de $10 \mathrm{~m} / \mathrm{s}$. Esta figura apresenta uma re-circulação de um vórtice (como no caso da Figura 2), porém confinado em uma região (a direita).

Para avaliar a influência da velocidade do fluxo livre $\left(\mathrm{U}_{\infty}\right)$ no exterior da cavidade sobre o perfil do vento médio e intensidade da turbulência, as análises foram realizadas com o valor médio de todas as posições dessas variáveis, para os experimentos onde a razão de aspecto é igual a 6 .

$O$ perfil do vento, adimensionalizado por $\left(\mathrm{U}_{\infty}\right)$, nãoapresenta grande variabilidade, verificando-se inclusive

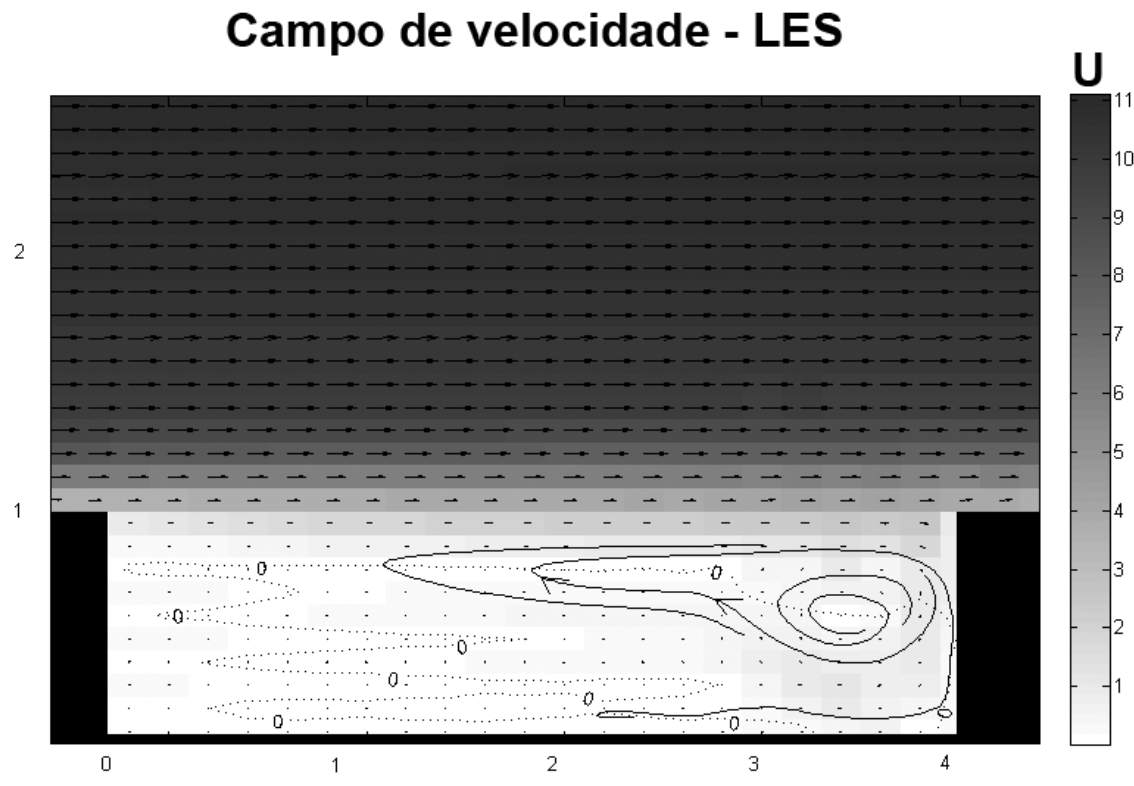

Figura 3 - Campos de velocidade obtidas por LES. Tons de cinza mais escuros correspondem a velocidades mais elevadas, as linhas cheias são linhas de corrente e as linhas pontilhadas representam regiões onde a componente horizontal do vento é igual a zero. A unidade nas direções x e z é adimensionalizada por $\mathrm{h}$. 
que as médias em posição desse perfil para cada experimento convergem para uma curva só, como pode ser visto na Figura 4a. A intensidade da turbulência (Figura 4b) mantém o mesmo formato do perfil, mas é inversamente proporcional a velocidade do fluxo livre para ambos os experimentos.

Para avaliar a influência da razão de aspecto da cavidade $(L / h)$ sobre o perfil médio do vento e intensidade da turbulência foram calculados os valores médios dessas variáveis em todas as posições para os vários tamanhos de cavidade, considerando o experimento realizado na velocidade de $5 \mathrm{~m} / \mathrm{s}$.

O perfil vertical de velocidade mostrou uma dependência do tamanho da cavidade apresentado na Figura 5a. Conforme o tamanho relativo da cavidade aumenta, o ponto de inflexão da média em todas posições do vento fica localizado em valores menores de $z / h$. Isso ocorre, tanto para os ensaios no túnel de vento, como para os experimentos em LES. O mesmo é observado para o valor mínimo local, observado apenas em alguns perfis do túnel de vento.

O perfil de intensidade da turbulência (Figura $5 b$ ) apresentou os valores máximos locais nas mesmas alturas onde se observa os mínimos locais do vento médio, ou seja, conforme o tamanho relativo da cavidade aumenta, os valores mínimos tendem a se posicionar em uma menor altura $(z / h)$, mais próximo da superfície. Isso não é observado para o experimento LES, que apresenta o máximo sempre no nível da superfície.

Aparentemente, essa dependência não está ligada somente a razão de aspecto da cavidade, mas também ao seu tamanho absoluto. Os experimentos físicos do TA-3 possuem comprimento na ordem de $10^{-1} \mathrm{~m}$ enquanto que, para os experimentos numéricos este comprimento é da ordem de $10^{2}$ m. Para comprimentos de menores, é observado que apenas uma pequena região do perfil, próxima ao fluxo livre, tem formato logaritmo. Na medida que o tamanho absoluto da cavidade aumenta, essa região com perfil logaritmo tende a se estender do fluxo livre até próximo a superfície. A altura onde ocorre o mínimo local da velocidade média (assim como o máximo da turbulência) é inversamente proporcional ao tamanho relativo da cavidade. Esta altura será na superfície a partir de um determinado tamanho absoluto da cavidade (estimado na ordem de $10^{0}$ ou $10^{1} \mathrm{~m}$ ). Essa hipótese é capaz de explicar as principais diferenças entre os experimentos físicos do túnel de vento e numérico obtidos pelo LES (Marciotto e Fisch, 2012).

Para avaliar a influência da posição no interior da cavidade foi adotada uma medida adimensional para a coordenada $x$, definida como uma posição adimensional $x / L$, que tem seu valor mínimo próximo a entrada da cavidade e valor máximo próximo a saída da cavidade. Foram feitas médias dos experimentos com todos as razões de aspecto de cavidade e velocidade do fluxo livre para cada posição relativa.

Para as posições relativas mais afastadas da borda de entrada ou origem, os perfis de velocidade, assim como o de intensidade da turbulência, tendem a se distribuir melhor verticalmente, uma vez que a região de produção de turbulência,

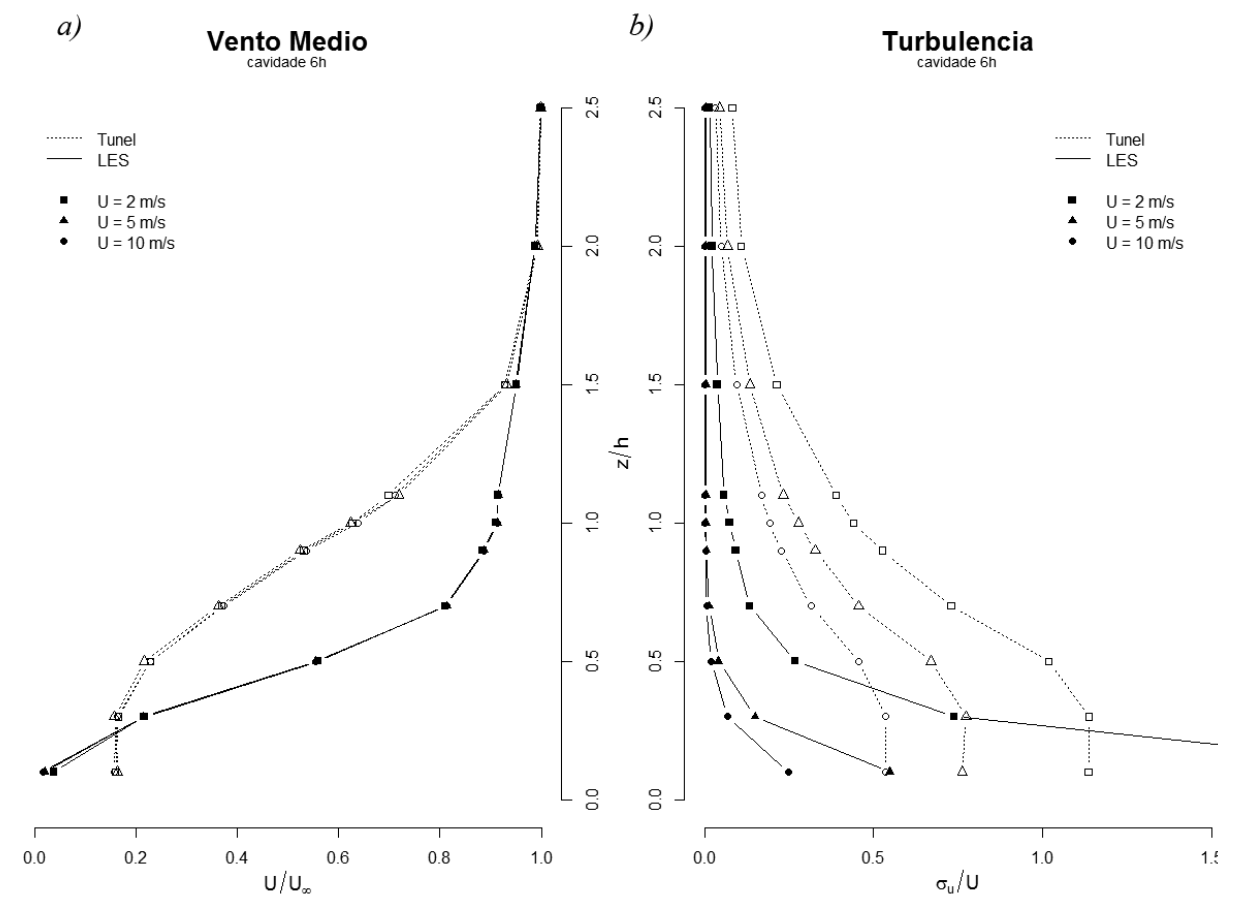

Figura 4 - perfil do vento (a) e da intensidade da turbulência (b) para os experimentos LES (Linhas cheias e marcadores preenchidos) e túnel de vento (linha pontilhada e marcadores sem preenchimento) com cavidade $6 \mathrm{~h}$. 


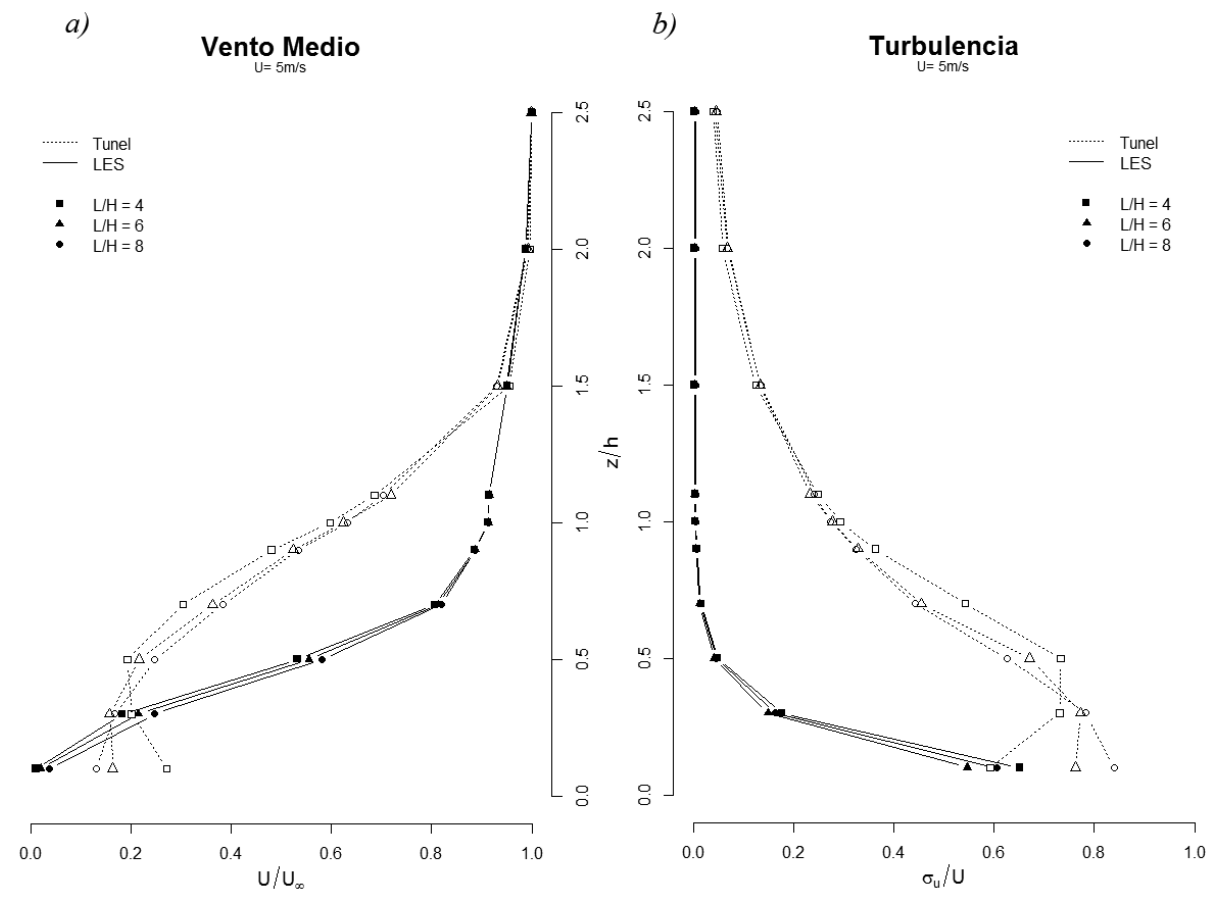

Figura 5 - perfil do vento (a) e da intensidade da turbulência (b) para os experimentos LES (Linha cheia e marcadores preenchidos) e túnel de vento (linha pontilhada e marcadores sem preenchimento) com velocidade de 5.

formada pela descontinuidade da cavidade, está mais afastada e a ECT é melhor distribuída (Figura 6a-6b).

A escala integral não apresenta um comportamento regular com a variação dos parâmetros analisados (velocidade do fluxo livre, tamanho da cavidade e posição relativa). Na Figura 7 são observados histogramas da distribuição de frequência do máximo local da Escala Integral Euleriana. As duas regiões onde ocorreram mais casos de máximos locais da escala integral significativos estão próximos à entrada da cavidade em $z / h=0,7$ (com módulo de $\Lambda_{u} / h \cong 0,6$ ) e também mais próximos a saída da cavidade em $z / h=1,5$ (com módulo de $\Lambda_{u} / h \geq 1,0$ ) para o experimento LES (como pode ser visto na Figura 7a), que são regiões preferenciais de formação de estruturas organizadas. Para o experimento em túnel de vento, os máximos locais mais significativos ocorrem próximo a saída da cavidade acima de $z / h$ $=0,1$ (com módulo de $\Lambda_{u} / h \geq 1,0$, embora máximos locais de pequeno módulo, comparado com sua vizinhança, ainda estejam presentes sem altura preferencial, como pode ser observado na Figura $7 a-7 b$.

Esta mesma verificação de dependência com a velocidade, tamanho da cavidade e posição relativa no interior da cavidade foi feita nos termos do balanço de ECT, Equação 10 , adimensionalizados (por $h / U^{3}$ ).

O termo de transporte (Figura 8) representa a soma dos termos I e II. O mesmo não apresenta dependência clara com a velocidade e tem uma dependência fraca em relação a razão de aspecto da cavidade (a Figura $8 \mathrm{~b}$ é o caso mais significativo), sendo tanto maior quanto menor o tamanho relativo da cavidade. Em relação à posição relativa, praticamente não há uma regularidade, exceto uma atenuação nos máximos de transporte, na medida em que se afasta da entrada da cavidade (ou origem).

O termo de cisalhamento (Figura 9) decresce com o aumento da velocidade do vento e com o tamanho da cavidade. Em relação a sua distribuição espacial, este apresenta seu máximo próximo à origem e decresce conforme se afasta da borda de entrada.

O termo de mistura turbulenta (Figura 10) não apresentou nenhuma dependência com a velocidade ou mesmo com o tamanho da cavidade. Apresentou uma fraca dependência em relação a posição, tendo seu máximo próximo à saída da cavidade, evidenciado nas alturas em que $z / h>1,0$.

O termo de dissipação (Figura 11) decresce conforme a velocidade do fluxo aumenta, sendo maior nas cavidades de maior razão de aspecto. Ele tem seu máximo próximo à entrada da cavidade decrescendo com a distância relativa. Esse termo foi obtido a partir do espectro de $U$, sem a aplicação de filtros como o representado pela Equação 11.

\section{CONCLUSÕES}

As características do vento e da turbulência no interior de cavidades rasas obtidas através de modelos idealizados, assim como sua dependência das características como velocidade 
a)

Vento Medio

b)

Turbulencia

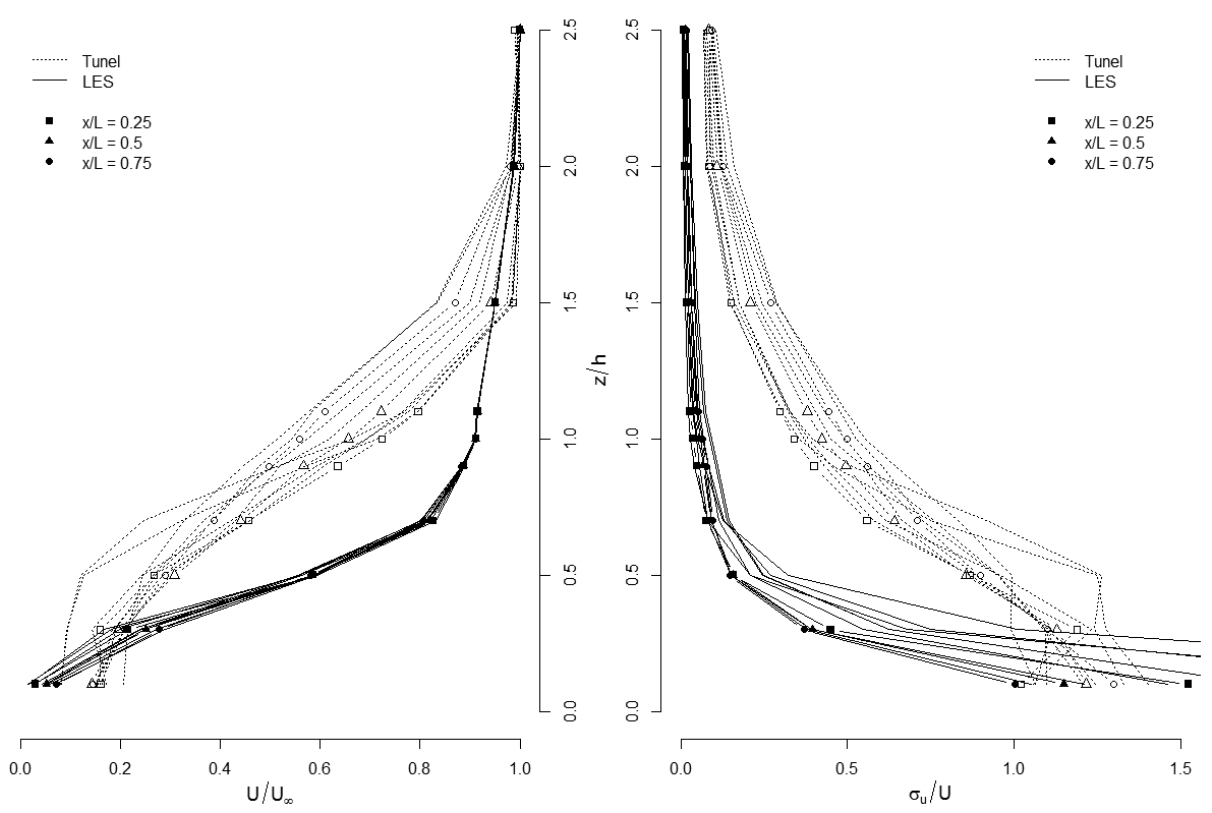

Figura 6 - Perfil do vento (a) e intensidade da turbulência (b) para os experimentos LES (Linhas cheias e marcadores preenchidos) e túnel de vento (linha pontilhada e marcadores sem preenchimento).

Máximo local da escala integral

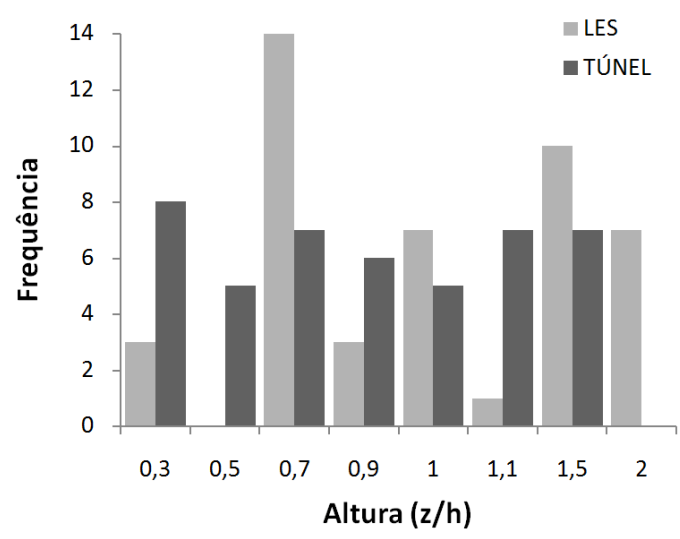

Altura do Máximo local

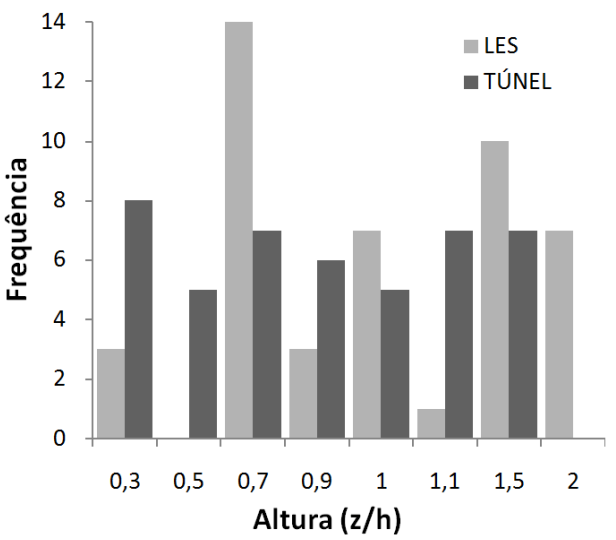

Figura 7 - Histogramas da distribuição de frequência do máximo local da Escala Integral Euleriana (a) e da altura onde ocorre o máximo local da Escala Integral Euleriana (b) para os experimentos LES e de túnel.

do fluxo livre, tamanho da cavidade e posição relativa foram apresentadas nesse trabalho. A hipótese de que algumas características do perfil do vento médio e da intensidade da turbulência estão ligadas às dimensões do modelo, ainda são válidas, embora estudos mais detalhados sejam necessários para essa confirmação.

Foram caracterizadas algumas regiões onde há indícios de estruturas organizadas no interior e acima da cavidade, sendo que essas estruturas de vórtices (Figuras 2 e 3 ) são responsáveis pela transformação de energia do escoamento médio externo a cavidade em ECT no interior da cavidade.
Os termos de transporte apresentaram uma variabilidade baixa, assim como o termo de mistura turbulenta. Isso pode estar ligado ao estado de quase-equilíbrio alcançado entre a difusão e o transporte de ECT no interior da cavidade, uma vez que determinadas estruturas organizadas observadas nos resultados são essencialmente transientes, mesmo em situações estacionárias.

\section{AGRADECIMENTOS}

Os autores agradecem ao apoio financeiro do $\mathrm{CNPq}$ (Processos 303720/2010-7, 471143/2011-1, 380026/2013-9, 
a)

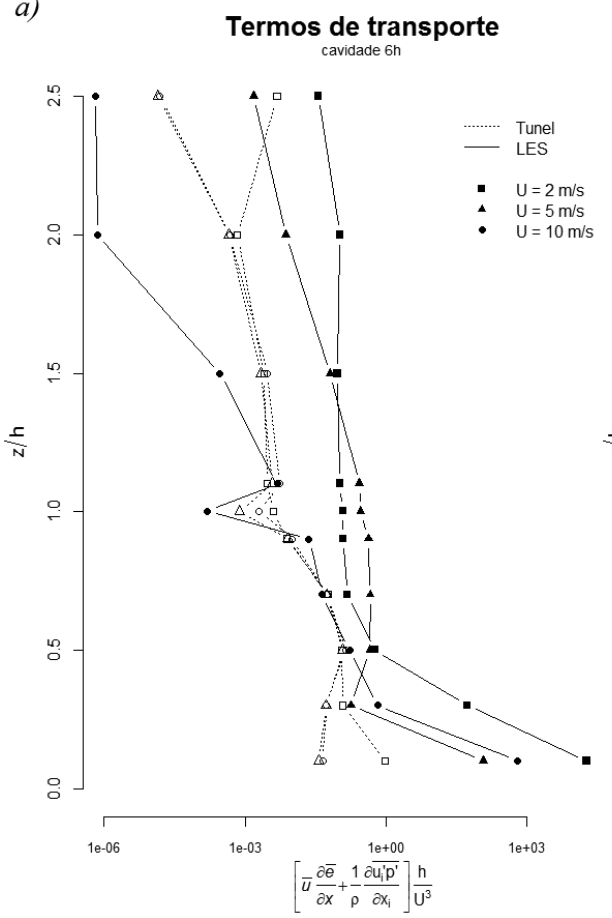

b)

Termos de transporte

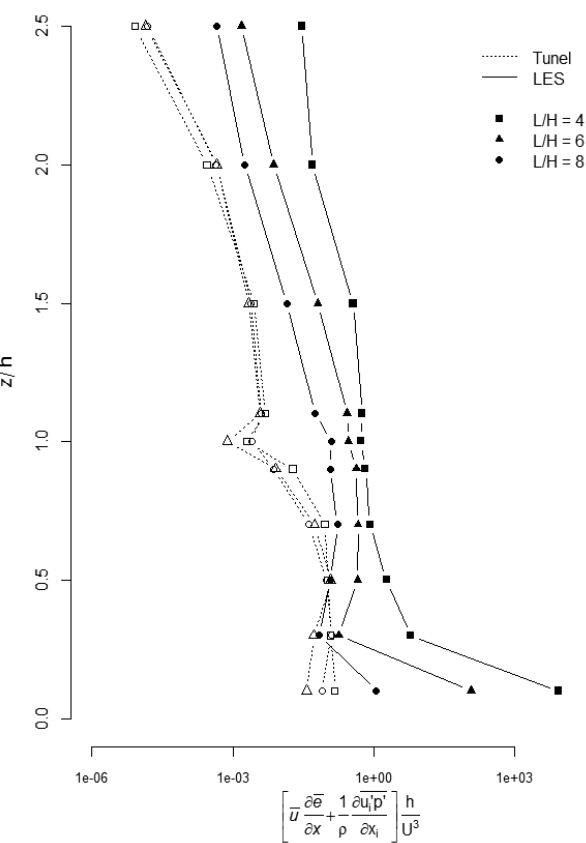

c)

Termos de transporte

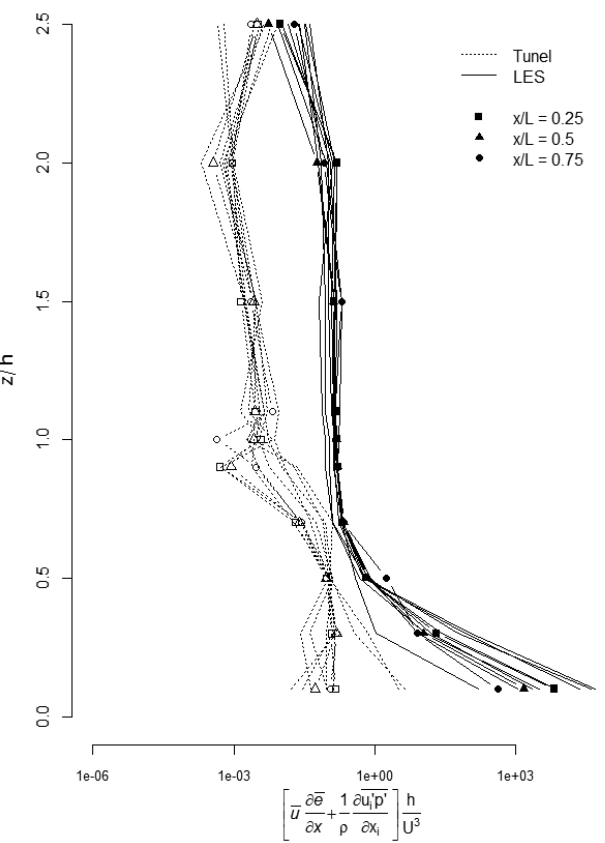

Figura 8 - Soma dos termos de transporte calculados para os experimentos LES (Linhas cheias e marcadores preenchidos) e túnel de vento (linha pontilhada e marcadores sem preenchimento). Variando a velocidade (a), razão de aspecto da cavidade (b) e posição relativa (c).

a)

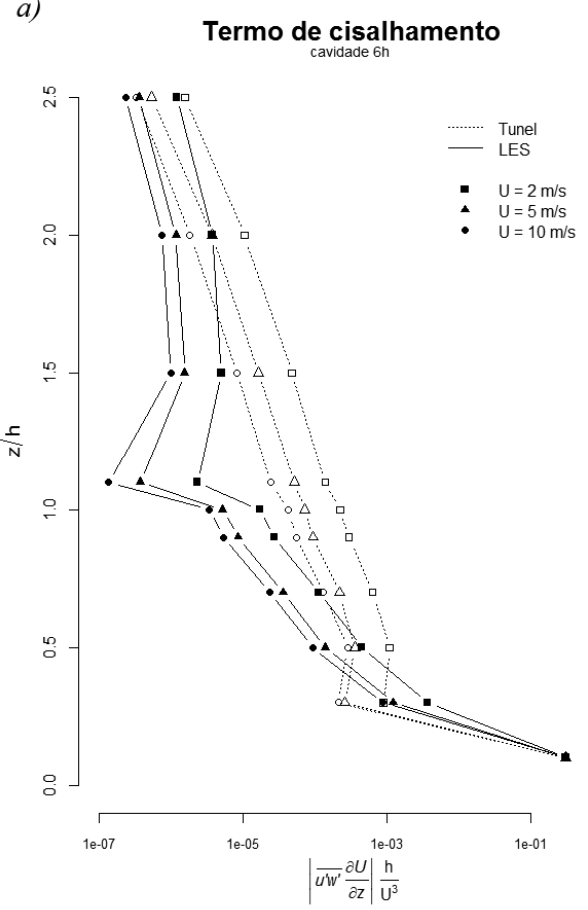

b)

Termo de cisalhamento

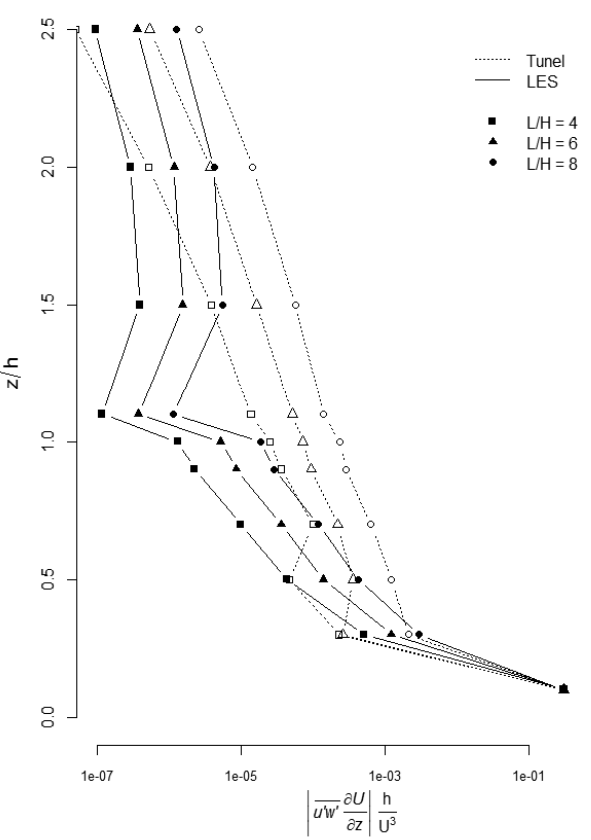

c)

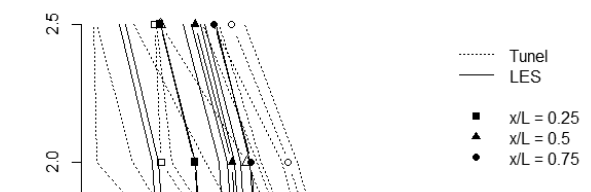

Figura 9 - Termo de cisalhamento calculado para os experimentos LES (Linhas cheias e marcadores preenchidos) e túnel de vento (linha pontilhada e marcadores sem preenchimento). Variando a velocidade (a), razão de aspecto da cavidade (b) e posição relativa (c). 
a)

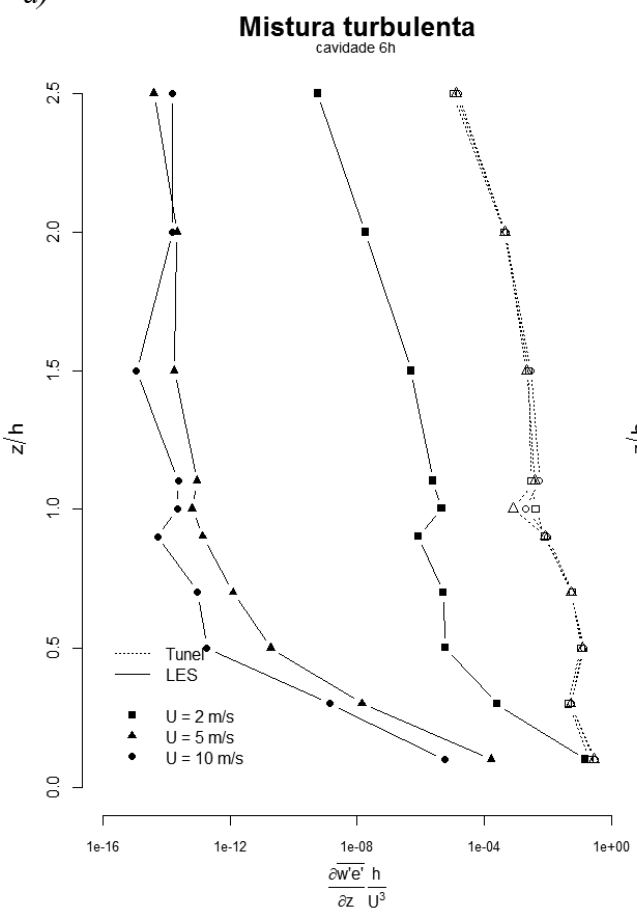

b)

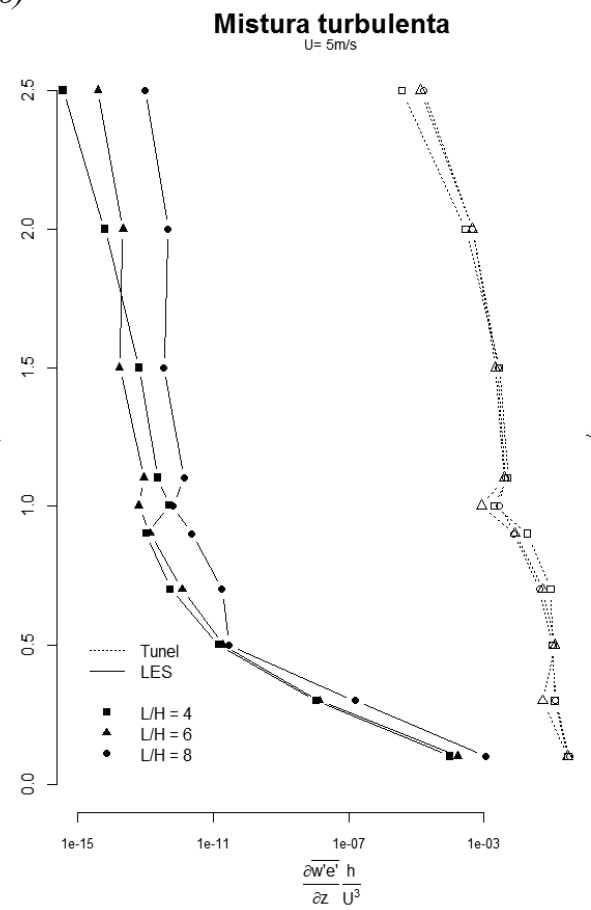

c)

\section{Mistura turbulenta}

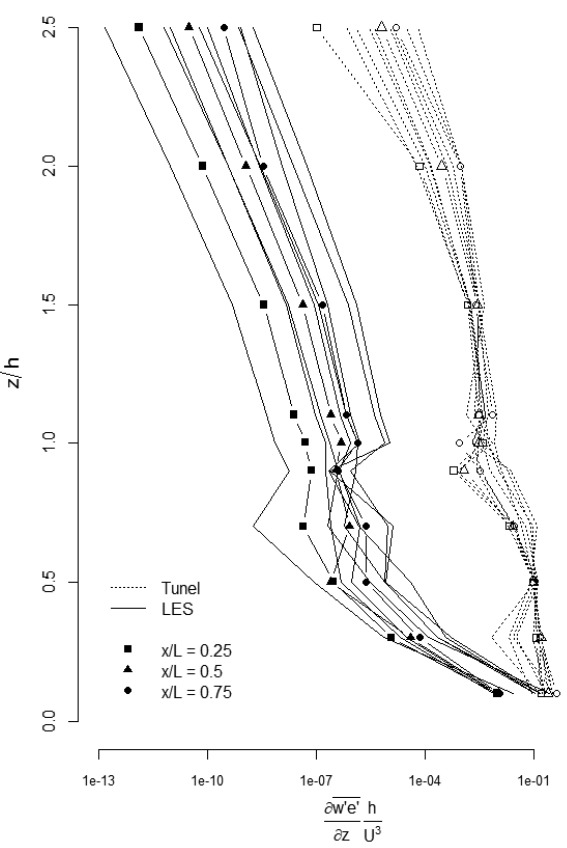

Figura 10 - Termo de mistura turbulenta calculado para os experimentos LES (Linhas cheias e marcadores preenchidos) e túnel de vento (linha pontilhada e marcadores sem preenchimento). Variando a velocidade (a), razão de aspecto da cavidade (b) e posição relativa (c).

a)

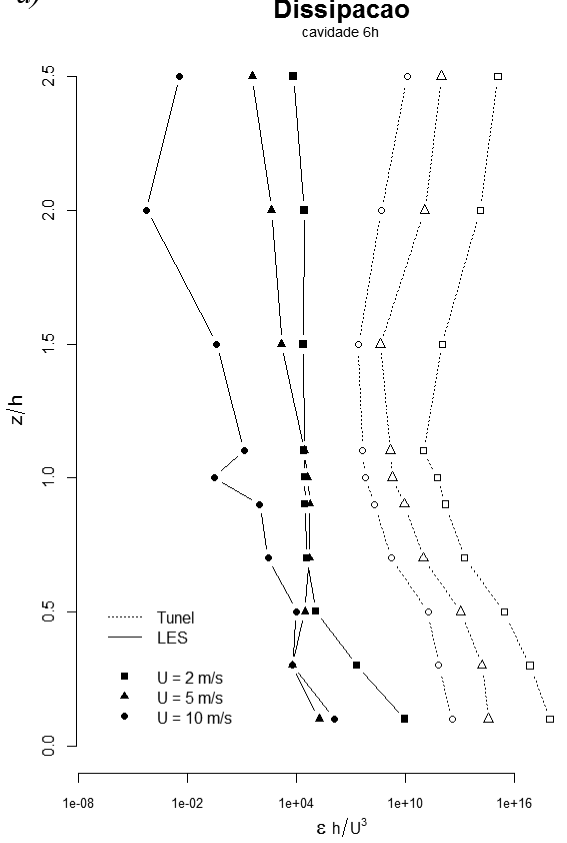

b)

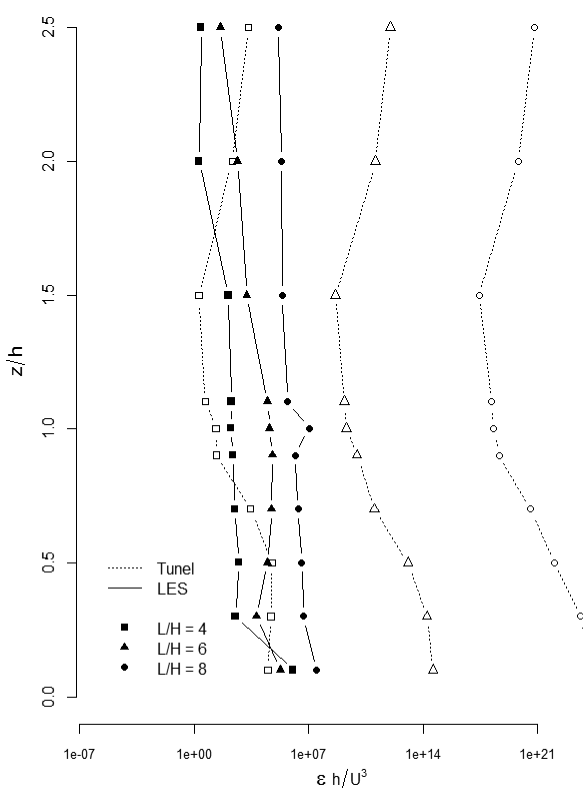

c)

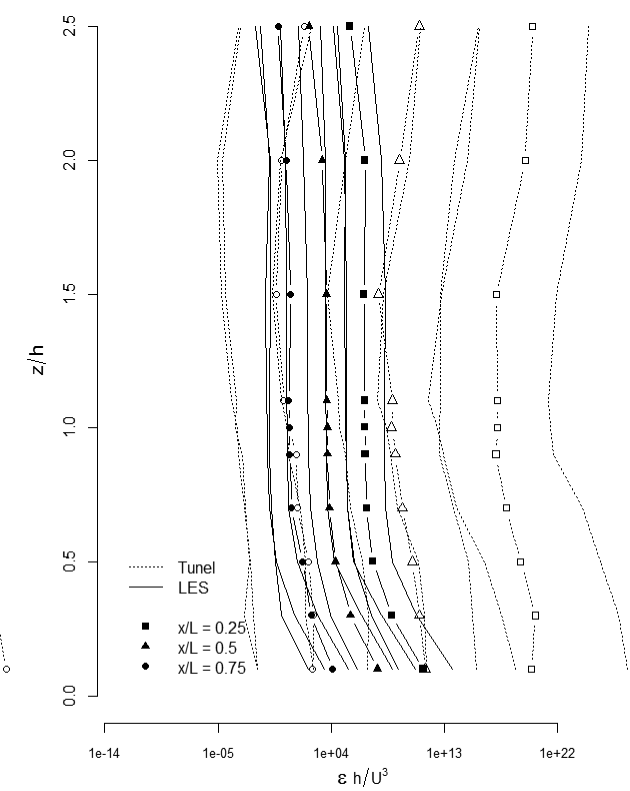

Figura 11 - Termo de dissipação calculado para os experimentos LES (Linhas cheias e marcadores preenchidos) e túnel de vento (linha pontilhada e marcadores sem preenchimento). Variando a velocidade (a), razão de aspecto da cavidade (b) e posição relativa (c). 
303720/2010-7) e a FAPESP (Processo 2010/16510-0). Esta pesquisa é uma contribuição do Instituto Nacional de Ciência e Tecnologia (INCT) para Mudanças Climáticas, financiado pelo projeto CNPq (Processo 573797/2008-0) e FAPESP (Processo 2008/57719-9).

\section{REFERÊNCIAS BIBLIOGRÁFICAS}

ARYA, S. P. Air Pollution Meteorology and Dispersion. New York, USA: Oxford University Press, 1999. 310 p.

AUBRUN, S.; KOPPMANN R.; LEITL B.; COERS M., M.; SCHAUB, A. Physical modelling of an inhomogeneous finite forest area in a wind tunnel - Comparison with field data and Lagrangian dispersion calculations. Agricultural and Forest Meteorology, v. 129, p. 121-135, 2004.

AVELAR, A.C.; BANHARA, J.R., FICO JR.; N.R., ANDRADE, C.R.; ZAPAROLI, E.L. Experimental and numerical investigation of roughness and three-dimensional effects on the flow over shallow cavities. In: 39th AIAA Fluid Dynamics Conference 22, 2009, San Antonio, Texas, 2009. p. 1-12.

BERG, J., MANN, J., BECLUMANN, A., COURTNEY, M.S., JORGENSEN, H.E. The Bolund Experiment, part I: flow over a steep three dimensional hill. Boundary-Layer Meteorology, v. 141, p. 219-243, 2011. (DOI 10.1007/s10546-011-9636-y).

BITENCOURT, D. P.; ACEVEDO, O. C. Modelling the interaction between a river surface and the atmosphere at the bottom of a valley. Boundary-Layer Meteorology, v. 129, n. 2, p. 309-321, 2008.

BOYCE, W. E.; DIPRIMA, RICHARD C. Elementary Differential equations and boundary value problems. 7 . ed. New York: Wiley Press, 2002. 745 p.

FOKEN, T. Micrometeorology. Heidelberg, Berlin: SpringerVerlag, 2006. 306 p.

JORGENSEN, F. E. Directional sensitivity of wire and fiber-film probes. DISA Information, v. 11, p. 31-37, 1971.

KRUIJT, B.; MALHI, Y.; LLOYD, J.; NOBRE, C.; MIRANDA, C.; PERREIRA, M.; CULF, A. GRACE, J. Turbulence statistics above and within two Amazon rain forest canopies.

Boundary Layer Meteorology, v. 94, p. 297-331, 2000.

LIM, H.C., CASTRO, I.P., HOXEY, R.P. Bluff bodies in deep turbulent boundary layers: Reynolds-number issues. Journal of Fluid Mechanics, vol. 571, p. 97-118, 2007. (doi:10.1017/S0022112006003223)

MARCIOTTO, E. R.; FISCH, G. Study of flow past an urban canyon model. In: ICUC8 - 8th International Conference on Urban Climates, UCD, Dublin, Ireland, p. 1-4, 2012.

MASON, P. J. Large-eddy simulation: a critical review of the technique. Quarterly Journal of the Royal Meteorological Society, v. 120, n. 515, p. 1-26, 1994.
MOENG, C. H.; WYNGARRD, J. C. Spectral analysis of largeeddy simulations of the convective boundary layer, Journal of the Atmospheric Sciences, v. 45, p. 3573-3587, 1988.

NEFF, D. E.; MERONEY, R. N. Wind-tunnel modeling of hill and vegetation influence on wind power availability. Journal of Wind Engineering \& Industrial Aerodynamics, v. 74-76, p. 335-343, 1988.

PANOFSKY, H. A.; DUTTON, J. A. Atmospheric Turbulence. New York: John Wiley \& Sons, 1984, 397 p.

PATTON, E.G.; SHAW, R.H.; JUDD, M.J.; RAUPACH, M.R. Large-eddy simulation of windbreak flow. Boundary-Layer Meteorology, v. 87, p. 275-306, 1998.

RAUPACH, M .R.; FINNIGAN, J. J.; BRUNET, Y. Coherent eddies and turbulence in vegetation canopies: the mixinglayer analogy. Boundary-Layer Meteorology, v. 78, p. 371-382, 1996.

RAUPACH, M .R.; THOM, A. S. Turbulence in and above plant canopies. Annual Review of Fluid Mechanics, v. 129, p.13-97, 1981.

RODRIGO, J. S.; BEECK, J. V.; DEZSÖ-WEIDINGER, G. Wind tunnel simulation of the wind conditions inside bidimensional forest clear-cuts: application to wind turbine sitting. Journal of Wind Engineering \& Industrial Aerodynamics, v 95, n. 7, p. 609-634, 2007.

SCHMIDT, H.; SCHUMANN, U. Coherent structure of the convective boundary layer from large-eddy simulations. The Journal of Fluid Mechanics, v. 200, p. 511-562, 1989.

SHAW, R. H.; SHUMANN, U. Large-Eddy Simulation of turbulent flow above and within a forest. Boundary-Layer Meteorology, v. 61, p. 47-64, 1992.

SMOLARKIEWICZ, P.K., MARGOLIN, L. G. On forward in-time differencing for fluids: an Eulerian/semi-Lagrangian non-hydrostatic model f or stratified flows. AtmosphereOcean, v. 35, p. 127-152, 1997.

SORBJAN, Z. Numerical study of penetrative and "Solid Lid" nonpenetrative convective boundary layers. Journal of the Atmospheric Sciences, v. 53, p. 101-112, 1996.

STULL, R. B. An Introduction to Boundary Layer Meteorology. Dordrecht, Holanda: Kluwer Academic Publishers, 1988, $666 \mathrm{p}$.

TILLMAN, J. E. The indirect determination of stability, heat and momentum fluxes in the atmospheric boundary layer from simple scalar variables during dry unstable condictions. J. Journal of Applied Meteorology and Climate, v. 11, p. 783-792, 1972.

VON RANDOW, C., MANZI, B., KRUIJT, B., OLIVEIRA, P.J. DE, ZANCHI, F.B., SILVA, R.L., HODNETT, M.G., GASH, J.H.C., ELBERS, J.A., WATERLOO, M.J., CARDOSO, F.L., KABAT, P. Comparative measurements and seasonal variations in energy and carbon exchange over forest and 
pasture in South West Amazonia. Theoretical and Applied Climatology, v. 78, n. 1-3, p. 5-26, 2004.

WYNGAARD, J.C. Turbulence in the Atmosphere, 2010, Cambridge University Press, $x \mathrm{p}$.
YAO, H.; COOPER, R. K.; RAGHUNATHAN S. Simulation of three-dimensional incompressible cavity flows. In: ICAS Congress. School of Aeronautical Engineering The Queen's University of Belfast, UK, 2000. p. 1-8. 